\title{
FORMATION OF AN INTEGRATED STRUCTURAL ASSESSMENT OF THE EXPORT POTENTIAL OF THE AVIATION COMPLEX
}

Kateryna Andriushchenko*

Department of Economics and Entrepreneurship

Kyiv National Economic University named after Vadym Hetman

54/1 Peremogy ave., 03057 Kyiv, Ukraine

https://orcid.org/0000-0002-6274-5310

Ganna Gurina

Department of Foreign Economic Activity Management of Enterprises

National Aviation University

1 Liubomyra Huzara ave., 03058 Kyiv, Ukraine

https://orcid.org/0000-0002-1419-4956

Elvira Danilova

Department of Foreign Economic Activity Management of Enterprises

National Aviation University

1 Liubomyra Huzara ave., 03058 Kyiv, Ukraine

(D) https://orcid.org/0000-0001-6036-7910

Viktoriia Zalizniuk

Department of World Economics

Kyiv National University of Trade and Economy

19 Kyoto str., 02156 Kyiv, Ukraine

https://orcid.org/0000-0002-7014-0207

Oleg Platonov

Department of Public Administration

Interregional Academy of Personnel Management

2 Frometovskaya str., 03039 Kyiv, Ukraine

(D) https://orcid.org/0000-0002-3059-5389

Vitalii Tkachuk

Department of Enterprise Economics Faculty of Economics

Kamianets-Podilskyi National Ivan Ohiienko University

61 Ohiienko str., 32300 Kamianets-Podilskyi, Ukraine

https://orcid.org/0000-0002-8529-9632

Article history: Received 23 April 2021, Received in revised form 19 May 2021, Accepted 28 May 2021, Available online 28 May 2021

\section{Abstract}

Successful operation and development of enterprises in modern conditions involves the expansion of markets. The company's entry into international markets requires the formation of its international competitive strategy, identification of competitive advantages in the markets of selected countries, and this, in turn, implies the need for export potential of the company. In determining the export potential of the aviation complex, it is necessary to consider the specific features of enterprises in this industry, among which we can highlight the features of the products of aviation enterprises and the features of the international aviation market. To qualitatively assess the level of economic potential, we propose to use a system of classification features, developed based on the well-known Harrington scale, but slightly modified by the authors in relation to the calculated data and available statistical information. The phases of the life cycle of the economic potential of the enterprise are determined. Not only the quantitative and qualitative level of economic potential are important, but also the changes associated with the passage of time. In order to determine the importance of indicators in each group, methods of component analysis of the characteristics 
of variation series of the results of the survey of experts were used. When comparing the variation of different features in one set with different average value, we use the relative indicators of variation - coefficients of variation. The obtained result together with the results of application of the method of component analysis allows us to conclude that in the formation of the integrated indicator of the first group (K1) it is enough to consider these five indicators, and the most important of them are two: technological processes to other activities.

\section{Keywords}

aviation enterprises, integrated structural assessment, export potential, aviation complex, export-import flows, international competitive strategy, competitive advantages, risks, foreign economic relations

\section{Introduction}

The level of development of the state's economy can be characterized by the size and structure of its exportimport flows. The higher the share of the country's participation in world exports of goods and services, and the structure of exports is dominated by goods of high-tech industries, the more efficient the country's economy. Successful operation and development of enterprises in modern conditions involves the expansion of markets. The company's entry into international markets requires the formation of its international competitive strategy, the identification of competitive advantages in the markets of selected countries, and this, in turn, implies the need for export potential of the company.

An important area of scientific research today is the development of the export potential of the aviation complex. Over the past 100 years, the development of the aviation complex has been characterized by rapid pace and has become an important sector of the world economy. Currently, the export potential of the aviation complex in most countries is in fierce competitive conditions, determined by trends in the world economy: global political instability, falling world oil prices, low domestic economic growth. Increasing the export potential is a necessary condition for the products of the aviation complex to enter the international market [1]. To solve this problem, it is necessary to use special tools to manage the development of the export potential of the aviation complex , contributing to the growth of competitiveness of goods in the international market. In addition, modern methods of managing the development of the export potential of the aviation complex must consider the non-tariff restrictions existing in the international aviation market and comply with the requirements and rules adopted by the WTO.

In determining the export potential of the aviation complex, it is necessary to consider the specific features of enterprises in this industry, among which we can highlight the features of the products of aviation enterprises and the features of the international aviation market. To enter the foreign market, products must strictly comply with international standards and technical regulations, as products are usually the next link in the production chain. The international aviation market is unstable: supply and demand in the market depend not only on trends in the development of the aviation complex, but also on the general level of economic and political stability of importing countries.

The analysis of the existing approaches to the definition of export potential showed that the definition of the export potential of the enterprise, corresponding to the specifics of the aviation complex, can be formulated as follows: the export potential of the aviation complex is the international market, and an opportunity of adaptation of the enterprise to continuous changes of external environment and achievement of the purposes of strategic development.

Even though there are many studies on the management of aviation complexes, there is no integrated structural assessment of the export potential of the aviation complex. In this article, we try to fill this gap, as well as shortcomings in the study of mechanisms for integrated structural assessment of the export potential of the aviation complex [2]. One of the tasks will be the development and formation of areas to ensure the company's ability to produce and supply competitive products to foreign markets, determining its entry into world markets, as well as its role in the economy determine the feasibility and objectives of the study. In the works of some authors, the export potential of the enterprise is considered as a special case of foreign economic potential. Many authors understand the export potential of the aviation complex as the level of competitiveness of its products in the foreign market. However, such an understanding does not affect the peculiarities of the organization and administration of production and foreign trade activities of the 
aviation complex. Considering the evolution of views on the essence of the concept of "export potential of the aviation complex", we can distinguish two areas of research of this scientific problem [3-5]. Resource direction of research of export potential: according to this concept export potential is a set of resources available to the aviation complex for production and sale of products in foreign markets, and the ability of the resources accumulated at the aviation complex to achieve the maximum possible export volume. The effective direction characterizes the considered concept from the position of result. The second approach determines the export potential of the aviation complex not only in terms of the availability of resources, achieved results or available opportunities, but also as a criterion for the competitiveness of products produced and exported. Each of these concepts has certain limitations, within which the emphasis is on the study of a particular aspect of the overall problem. Identifying the complex nature of the export potential of airlines gave grounds to prove the need to develop a methodology for export potential, which requires clarification and supplementation of their categorical and conceptual apparatus. Export potential is proposed as an organized set of internal and external economic opportunities and resources (discovered or hidden), which create conditions for development and ensure the implementation of strategic and tactical goals of the enterprise in the field of aviation, guided by adequate economic development strategy.

In our opinion, it is impossible to sufficiently agree with any of the presented approaches, as economic potential is a complex, complex education. Each approach focuses only on its individual aspects, parts. Economic potential, we believe, is a kind of tool that allows you to choose the most effective way to use the total potential of the enterprise and develop directions for its development strategy [6]. Therefore, the concept of "economic potential" should be based on the process of goal setting. The maximum possible output cannot be the goal of the company without focusing on the customer and market conditions.

\section{Methods}

In the process of implementing a synergetic approach to determine the normalized indicators, we use formulas based on deviations ( $x i j-a)$ and standardized by the variational scale $\left(x_{\max }-x_{\min }\right)$ :

- for indicators-stimulants (the more, the better), the normalized indicator Ui is calculated as follows:

$$
Y_{\mathrm{ij}}=\frac{X_{\mathrm{ij}}-\min X_{\mathrm{ij}}}{\max X_{\mathrm{ij}}-\min X_{\mathrm{ij} j}} .
$$

where $\quad Y_{\mathrm{ij}}$ - is the normalized $\mathrm{i}$-th indicator in the j-th population;

$X_{i j}$ - the value of the $\mathrm{i}$-th indicator in the $\mathrm{j}$-th population;

$\min X_{\mathrm{i}}$ - the minimum value of the i-th indicator;

$\max X_{\mathrm{i}}$ - the maximum value of the i-th indicator.

That is, the larger the actual value of $X$ and $j$ within the range of their oscillations, the closer to 1 will be the value of $B$ and $j$.

- for indicators-disincentives (the less, the better), In ij is calculated using the formula:

$$
Y_{\mathrm{i} j}=\frac{\max X_{\mathrm{i} j}-X_{\mathrm{i} j}}{\max X_{\mathrm{i} j}-\min X_{\mathrm{i} j}}
$$

The integrated indicator for each component of economic potential is defined as the average value of the selected coefficients for a certain calendar period, due to the equivalence of all indicators of each group:

$$
I_{j}=\frac{\sum Y_{i j}}{n}
$$

where $\quad Y_{\mathrm{i} j}$ is the normalized $i$ - th indicator in the $j$-th set;

$n$ - is the number of indicators of a certain group.

To calculate the integrated indicator of the level of economic potential of the enterprise it is necessary to determine the weights for each component of the potential using the method of expert assessments (Table 1). 
The integrated indicator of the level of economic potential of the enterprise is calculated by the formula:

(4)

$$
I=\sum_{i=1}^{n} I_{j} \times r_{j}
$$

where $\quad I_{j}$ - is an integral indicator of the $j$-th component of economic potential;

$r_{j}$ - weight of the $j$-th group of indicators.

Table 1. Weights of components of the general economic potential of the enterprise (based on an expert method). Source: summarized by the author for $[7,8]$

\begin{tabular}{|l|c|c|}
\hline \multicolumn{1}{|c|}{ Components } & Score & Weights \\
\hline Production and technological & 22 & 0.22 \\
\hline Labor & 17 & 0.17 \\
\hline Financial & 21 & 0.21 \\
\hline Marketing & 14 & 0.14 \\
\hline Organizational and managerial & 12 & 0.12 \\
\hline Rehabilitation & 8 & 0.08 \\
\hline Strategic & 6 & 0.06 \\
\hline Total & 100 points & 1 \\
\hline
\end{tabular}

To qualitatively assess the level of economic potential, we propose to use a system of classification features, developed based on the well-known Harrington scale, but slightly modified by the authors in relation to the calculated data and available statistical information (Table 2).

The next stage of the synergetic approach is to determine the phase of the life cycle of the economic potential of the enterprise $[5,9]$. Not only the quantitative and qualitative level of economic potential are important, but also the changes associated with the passage of time.

Table 2. Scale for assessing the integrated indicator of the level of economic potential of the enterprise. Source: systematized by the author.

\begin{tabular}{|c|c|}
\hline $\begin{array}{c}\text { The interval of the integrated indicator of the level of } \\
\text { economic potential }\end{array}$ & $\begin{array}{c}\text { The level of economic potential of the } \\
\text { enterprise }\end{array}$ \\
\hline$[0 ; 0.2]$ & critical \\
\hline$[0.2 ; 0.37]$ & low \\
\hline$[0.37 ; 0.57]$ & acceptable \\
\hline$[0.57 ; 0.7]$ & sufficient \\
\hline$[0.7 ; 0.9]$ & high \\
\hline$[0.9 ; 1]$ & reference \\
\hline
\end{tabular}


This is because the same quantitative value can correspond to different phases, because the graphical form of the life cycle involves the possibility of points with the same coordinates on the B axis (level of economic potential) at different intervals of the curve and, accordingly, at different stages of the life cycle.

\section{Results and discussion}

To determine the weight of indicators in each group, methods of component analysis of the characteristics of variation series of the results of the survey of experts were used.

When comparing the variation of different features in one set with different average value, we use the relative indicators of variation - coefficients of variation. They are calculated as the ratio of absolute variations to the arithmetic mean and expressed as a percentage [10]. The results obtained are shown in table 3 by study groups.

Table 3. Coefficients of variation of indicators $X_{\mathrm{ij}}, \%$. Source: developed by the author.

\begin{tabular}{|c|c|c|c|c|c|c|c|}
\hline$i$ & 1 & 2 & 3 & 4 & 5 & 6 & 7 \\
\hline 1 & 25.85 & 14.96 & 13.34 & 15.41 & 30.44 & - & - \\
\hline 2 & 25.60 & 10.30 & 11.77 & 12.51 & 12.51 & 15.55 & 11.76 \\
\hline 3 & 24.98 & 13.17 & 13.76 & 12.99 & 13.73 & 21.77 & - \\
\hline 4 & 16.57 & 15.65 & 14.65 & 13.27 & 12.68 & 11.49 & 15.68 \\
\hline
\end{tabular}

$X_{i j}$ is a relative value that characterizes the weight of each indicator in the group, it takes values from 0 to 1 (from 0 to $100 \%), i$ - group, $j$ - indicator).

For indicators that characterize the resource potential of the enterprises of the aviation complex, the following results were obtained $X_{11}=0.2585, X_{12}=0.1496, X_{1 a}=0.1334, X_{14}=0.1541, X_{15}=0.3044$

The obtained result together with the results of application of the method of component analysis allows us to conclude that when forming the integrated indicator of the first group $\left(K_{1}\right)$ it is enough to take into account these five indicators, and the most important of them are two: $X_{11}$ - capacity utilization factor and $X_{14}$ adaptability factor technological processes to other activities $\left(X_{11}+X_{14}=25.85+30.44=56.29\right)$.

For the second group $\left(K_{2}\right)$ - important indicators are: $X_{21}$ - management efficiency and $X_{26}$ - the level of competence, which together amount to almost $42 \%$ of the share of the group of human resources of the aviation complex.

Significant indicators for the coefficient of the third group $\left(\mathrm{K}_{3}\right)$, which characterizes the efficiency of the aviation complex, were $X_{31}$ - an indicator of overall profitability and $X_{36}$ - an indicator of labor productivity. The total weight of these indicators, within the coefficient of export potential of aviation enterprises, is $47 \%$.

Other indicators are equilibrium to determine the assessment of the efficiency of the airlines of the complex and average $13 \%$.

When forming the generalizing coefficient of the fourth group $\left(\mathrm{K}_{4}\right)$ - assessment of the financial condition of the enterprises of the aviation complex of Ukraine, all indicators are equivalent and make on average the specific weight of the coefficient of the group about $13 \%$. Although we should pay attention to the absolute liquidity ratio - $X_{41}$ - which is $16 \%$ of the weight of the ratio, and the indicators $X_{42} \approx X_{47}$ and in total are about $32 \%$. 
We evaluate the reliability of the obtained results according to Pearson's criterion $x^{2}$, which allows to determine the consistency of experts' opinions on the impact of weights on the value of the resulting indicator of the coefficient of export potential of the aviation complex of Ukraine [11]. This method is based on the calculation of the concordance coefficient:

$$
W=\frac{12 \sum_{i=1}^{k} \Delta_{i}^{2}}{m^{2}\left(k^{3}-k\right)-m \sum_{i=1}^{m} T_{i}},
$$

where $\quad k$ - is the number of indicators;

$m$ - number of experts;

$$
T_{i}=\sum_{t_{i}}\left(t_{i}^{a}-t_{i}\right)
$$

where $\quad t_{i}$ - the number of identical estimates in the $i$-th indicator;

the sum of squares in deviations of the sum of variation coefficients of indicators of weight of each expert from the general average sum:

$$
\sum_{j=1}^{k} \Delta_{j}^{2}=\sum_{j=1}^{k}\left(\sum_{i=1}^{m} d_{i j}-\frac{\sum_{i=1}^{k} \sum_{j=1}^{m} d_{i j}}{k}\right)^{2}
$$

where $\quad d_{i j}-$ is the value of the $j$-th indicator according to the $i$ - th expert.

Consistency expert evaluations assessed the criterion Pearsons $\chi^{2}$, the observed value is calculated using the formula:

$$
\chi^{2}=m(k-1) W_{x}
$$

critical and is determined by the data, the given significance $\alpha$ and number of degrees of freedom $s=k-1$.

Determine the consistency of the expert assessment for each group of indicators, considering the results obtained.

Then the total average amount:

$$
\begin{gathered}
\frac{\sum_{i=1}^{k} \sum_{j=1}^{m} d_{i j}}{k}=\frac{2695}{25}=107.8, \\
\sum_{j}^{k} \Delta^{2}=92.84, \\
\sum_{i=1}^{m} T_{i}=48
\end{gathered}
$$

Observed value of the criterion: $\chi^{2}=27 \times(25-1) \times 0.098=63.5$

Critical value: $\gamma^{2}(0.05 ; 5)=11.07$

Since the observed value is more critical, with a probability of 0.95 , the obtained expert assessment can be considered consistent. 
According to the estimates conducted surveillance ratios calculated resource potential claim enterprises of aviation sector and human resources, weightings efficiency of enterprises aviation sector and financial condition [2]:

$$
\begin{array}{ll}
K_{1}=\sqrt[5]{\prod_{j=1}^{5} X_{1 j}}=0.1891 ; & K_{2}=\sqrt[7]{\prod_{j=1}^{7} X_{2 j}}=0.1366 ; \\
K_{a}=\sqrt[6]{\prod_{j=1}^{6} X_{a j}}=0.1605 ; & K_{4}=\sqrt[7]{\prod_{j=1}^{7} X_{4 j}}=0.1418 ;
\end{array}
$$

Based on the results of the calculations, we determine the group weighting factors according to the formula:

(9)

$$
K_{\mathrm{i}}=\frac{k_{\mathrm{i}}}{\sum_{\mathrm{i}=1}^{4} k_{\mathrm{i}}}
$$

where $k_{\mathfrak{i}}$ - coefficients of variation and - that group;

$K_{\mathrm{i}}$ - weighting factor and - that group.

To calculate formulas integral factor export potential claim and reception in aviation complex weight coefficients define groups directly to experts. (Table 4).

Table 4. Weight of groups according to rating assessment. Source: developed by the author

\begin{tabular}{|c|c|c|c|c|c|c|c|c|c|c|c|c|c|c|c|c|c|c|c|c|c|c|c|c|c|}
\hline Group & \multicolumn{10}{|c|}{ Expert rating,\% } \\
\cline { 2 - 15 } & 1 & 2 & 3 & 4 & 5 & 6 & 7 & 8 & 9 & 10 & 11 & 12 & 13 & 14 & 15 & 16 & 17 & 18 & 19 & 20 & 21 & 22 & 23 & 24 & 25 \\
\hline 1 & 20 & 25 & 20 & 20 & 10 & 20 & 25 & 25 & 20 & 30 & 15 & 10 & 40 & 25 & 20 & 20 & 25 & 30 & 35 & 60 & 35 & 30 & 40 & 35 & 50 \\
\hline 2 & 40 & 30 & 25 & 20 & 20 & 50 & 20 & 20 & 25 & 20 & 25 & 30 & 22 & 28 & 30 & 10 & 50 & 50 & 15 & 20 & 40 & 30 & 40 & 35 & 25 \\
\hline 3 & 20 & 25 & 25 & 35 & 40 & 15 & 25 & 25 & 30 & 25 & 35 & 25 & 20 & 25 & 20 & 40 & 15 & 20 & 25 & 10 & 15 & 20 & 10 & 20 & 10 \\
\hline 4 & 20 & 20 & 30 & 25 & 30 & 15 & 30 & 30 & 25 & 25 & 25 & 35 & 18 & 22 & 30 & 30 & 10 & 0 & 25 & 10 & 10 & 20 & 10 & 10 & 15 \\
\hline
\end{tabular}

Applying the scheme of calculating the weight of the coefficients, we obtain $\mathrm{K}_{1}=0.28, \mathrm{~K}_{2}=0.29, \mathrm{~K}_{3}=0.23, \mathrm{~K}_{4}$ $=0.20$.

At this stage of the study, the weight of the groups and their indicators, the results are presented in (Table 5).

Note that at the first stage of the experiment to calculate the integrated coefficient of export potential of airlines used the formula of the geometric mean, i.e., the generalized indicator of export potential was calculated as the average value of the obtained coefficients (since each of the four proposed coefficients).

To obtain a more accurate formula for determining the integrated coefficient of export potential of aviation enterprises, which would consider the impact of each component on its value, we use the methods of factor analysis.

Let us determine the influence of indicators of export potential in each of the groups on the generalized coefficient of export potential of airlines [10]. 
Table 5. Weight of groups and their indicators. Source: developed by (Gurina G.)

\begin{tabular}{|c|c|c|c|}
\hline № & Groups & Indexes & Validity \\
\hline \multirow[t]{5}{*}{1} & \multirow{5}{*}{$\begin{array}{l}\text { Resource } \\
\text { potential }\end{array}$} & 1. Capacity utilization factor & 0.6 \\
\hline & & 2. Coefficient of use of fixed assets & 0.63 \\
\hline & & 3. Staff utilization rate in & 1 \\
\hline & & 4. $\quad$ Coefficient of job security & 0.16 \\
\hline & & $\begin{array}{l}\text { 5. Coefficient of adaptability of technological } \\
\text { processes to other activities }\end{array}$ & 0.28 \\
\hline \multirow[t]{7}{*}{2} & \multirow{7}{*}{$\begin{array}{l}\text { Human } \\
\text { resources }\end{array}$} & 1. Management efficiency & 0.7335 \\
\hline & & $\begin{array}{l}\text { 2. The share of management staff with higher } \\
\text { education }\end{array}$ & 0.77 \\
\hline & & 3. $\quad$ Cost-effectiveness of the management staff & 0.231 \\
\hline & & 4. Development of the management staff & $\begin{array}{l}0.037 \text { the most } \\
\text { common }\end{array}$ \\
\hline & & $\begin{array}{l}\text { 5. Educational qualification was Evan management } \\
\text { personnel }\end{array}$ & 0.67 \\
\hline & & 6. Competence of workers in & 0.98 \\
\hline & & 7. Evaluation of the creative industry & 0.32 \\
\hline \multirow[t]{6}{*}{3} & \multirow{6}{*}{$\begin{array}{l}\text { Performance } \\
\text { appraisal } \\
\text { and } \\
\text { enterprises }\end{array}$} & 1. Profitability of the general (main activity) & 0.11 \\
\hline & & 2. $\quad$ Return on fixed assets & 0.023 \\
\hline & & 3. $\quad$ Return on investment & 0.24 \\
\hline & & 4. The turnover ratio of the asset in & 0.27 \\
\hline & & 5. Coefficient of suitability of fixed assets & 0.14 \\
\hline & & 6. $\quad$ Productivity & 0.938 \\
\hline \multirow[t]{7}{*}{4} & \multirow{7}{*}{$\begin{array}{l}\text { Rating } \\
\text { financial } \\
\text { state }\end{array}$} & 1. The ratio of the absolute liquidity & 0.17 \\
\hline & & 2. Current ratio & 0.2 \\
\hline & & 3. Financing ratio (coverage) & 0.1 \\
\hline & & 4. Coefficient of autonomy & 0.7 \\
\hline & & 5. Equity maneuverability ratio & 0.45 \\
\hline & & 6. Investment ratio & 0.202 \\
\hline & & 7. Financial ratio & 0.98 \\
\hline
\end{tabular}

Since a multiplicative model of the form $f=x y z q$ is used for its calculation, we apply the integrated method of factor analysis, which is based on the summation of increments of a function defined as a partial derivative multiplied by the increment of the argument at infinitesimal intervals [12].

The structure of the factor system has the form:

$$
\Delta f=x_{1} y_{1} z_{1} q_{1}-x_{0} y_{0} z_{0} q_{0}=A_{z}+A_{y}+A_{z}+A_{q}
$$


We construct $\mathrm{n}$-integral expressions that express the integral weights of the respective groups of indicators:

$$
\begin{aligned}
& A_{x}=\int_{0}^{\Delta x} y_{x}^{\prime} z_{x}^{\prime} q_{x}^{s}=\frac{1}{6} \Delta x\left\{3 q_{0} y_{0} z_{0}+y_{1} q_{0}\left(z_{1}+\Delta z\right)+q_{1} z_{0}\left(y_{1}+\Delta y\right)+z_{1} y_{0}\left(q_{1}+\Delta q\right)\right\}+\frac{1}{4} \Delta x \Delta y \Delta z \Delta q^{s} \\
& A_{y}=\int_{0}^{\Delta x} x_{x}^{y n} z_{x}^{s} q_{x}^{s}=\frac{1}{6} \Delta y\left\{3 q_{0} x_{0} z_{0}+x_{1} q_{0}\left(z_{1}+\Delta z\right)+q_{1} z_{0}\left(x_{1}+\Delta x\right)+z_{1} x_{0}\left(q_{1}+\Delta q\right)\right\}+\frac{1}{4} \Delta x \Delta y \Delta z \Delta q^{x} \\
& A_{z}=\int_{0}^{\Delta x} x_{x}^{z y} y_{x}^{s} q_{x}^{s}=\frac{1}{6} \Delta z\left\{3 q_{0} x_{0} y_{0}+q_{1} x_{0}\left(y_{1}+\Delta y\right)+y_{1} q_{0}\left(y_{1}+\Delta y\right)+x_{1} y_{0}\left(q_{1}+\Delta q\right)\right\}+\frac{1}{4} \Delta x \Delta y \Delta z \Delta q^{s} \\
& A_{q}=\int_{0}^{\Delta x} x_{x}^{q^{p}} z_{x}^{s} y_{x}^{s}=\frac{1}{6} \Delta q\left\{3 y_{0} x_{0} z_{0}+x_{1} z_{0}\left(y_{1}+\Delta y\right)+y_{1} z_{0}\left(x_{1}+\Delta x\right)+x_{1} y_{0}\left(z_{1}+\Delta z\right)\right\}+\frac{1}{4} \Delta x \Delta y \Delta z \Delta q^{x}
\end{aligned}
$$

where: $\quad x_{\mathrm{i}}=\sqrt[4]{K_{1}^{(\mathrm{i})}}, y_{\mathrm{i}}=\sqrt[4]{K_{2}^{(\mathrm{i})}}, z_{\mathrm{i}}=\sqrt[4]{K_{\mathrm{a}}^{(\mathrm{i})}}, q_{\mathrm{i}}=\sqrt[4]{K_{4}^{(\mathrm{i})}}$,

To calculate the influence of the integrated weights of the groups, the data obtained during two studies were used. The results are presented in table 6 .

Table 6. The data obtained during the research.

\begin{tabular}{|c|c|c|c|c|c|c|c|}
\hline$x_{1}$ & $y_{1}$ & $z_{1}$ & $q_{1}$ & $x_{0}$ & $y_{0}$ & $z_{0}$ & $q_{0}$ \\
\hline 0.82 & 0.94 & 0.91 & 0.96 & 0.79 & 0.87 & 0.93 & 0.92 \\
\hline
\end{tabular}

$\Delta f=0.2463144-0.16217216=0.0851317$;

$$
\begin{gathered}
A_{x}=0.023484, A_{x}=0.025539, A_{x}=0.020432, A_{x}=0.015324, \\
a_{1}=\frac{A_{x}}{\Delta f}=0.28, \quad a_{2}=\frac{A_{y}}{\Delta f}=0.29, \quad a_{a}=\frac{A_{z}}{\Delta f}=0.23, \quad a_{4}=\frac{q}{\Delta f}=0.20,
\end{gathered}
$$

Consequently, the export potential integral factor and reception aviation industry of Ukraine affected by:

- $\quad$ resource potential ratio by $28 \%$;

- $\quad$ personnel ratio by $29 \%$;

- coefficient for assessing the efficiency of the aviation complex by $23 \%$;

- coefficient of assessment of financial condition by $20 \%$.

Then, to determine the value of the integrated coefficient of the export potential of the aviation complex can be used the following formula:

$$
K_{\mathrm{p}}=0.28 K_{1}+0.29 K_{2}+0.23 K_{\mathrm{a}}+0.20 K_{4}
$$

The integrated coefficient of export potential must meet the requirements dictated by the convenience of its further use, namely [8]:

- $\quad$ it must be a numerical measure, which in an integrated form quite objectively expresses the level of all the most important indicators of the export potential of the enterprise;

- its value should depend on all the main characteristics that may affect the export potential, considering their significance - "weight"; 
- its value must have its own unit of measurement (the most natural for this type of coefficient is the measurement in shares or\%);

- $\quad$ to compare the values of the integrated coefficient of export potential there should be a natural and convenient scale;

- since the integrated coefficient of export potential can be calculated mainly based on subjective assessments (expert assessments), the method of its determination should minimize possible bias and give a reliable result with any selected level of reliability.

According to the author, the proposed methodological approach allows to satisfy all the formulated requirements. A preliminary survey of experts made it possible to determine the full range of indicators that form the integrated coefficient of export potential of the enterprises of the aviation complex, to choose the most significant among them, to group and determine their importance [13].

The generalized coefficients for each group of indicators are calculated considering the magnitude and influence of the coefficients of the formative factors.

After calculating the coefficient of export potential, it is necessary to identify its level on a scale to assess its value.

To determine the scale of assessment of the integrated coefficient of export potential of airlines, a variance analysis of alternative and nominal characteristics was used and the standard deviation of the alternative series of distribution of integrated weights of groups was determined [1].

Quantitative variation is expressed by two nominal values: the presence of an impact on the coefficient of export potential, which is taken as 1 (q), and its absence, which is denoted as 0.

Then $p$ is the fraction of units of integrated weights of groups, which is calculated by the formula and obtained the maximum critical value of the scale of export potential:

$$
\begin{gathered}
p=\sqrt[4]{a_{1} \times a_{2} \times a_{3} \times a_{4}} \\
a_{i,}, i=\overline{1_{x} 4} \text { - integral weights of groups }
\end{gathered}
$$

In accordance

$$
q=1-p
$$

Therefore, the standard deviation of the integral weights from the nominal value $(\sigma)$, is calculated by the formula:

$$
\sigma=\sqrt{p q}
$$

The calculations form the result: $p=\sqrt[4]{0.28 \times 0.29 \times 0.23 \times 0.20}=0.24$ then $q=1-0.24=0.76$

therefore, $\sigma=\sqrt{0.24 \times 0.76}=0.47$

The obtained result of the standard deviation of the integrated weights makes it possible to determine the length of the interval of a sufficient level of export potential of the enterprise, which is 0.47 .

Using the rule, $3 \sigma$ we construct a scale in units of standard deviation, setting the size of the interval $\frac{1}{2} \sigma$, and get the length of the interval of the next level (low). Then the interval of scalability of adaptability of the enterprise is defined as $2 \times \frac{1}{2} \sigma=\sigma=0.47$, that is the difference between the upper limits of low and sufficient levels, and the difference between the lower limit of low level and the upper limit of sufficient level should be

$$
3 \times \frac{1}{2} \sigma=\frac{a}{2} \sigma=0.63
$$


The deepening of the crisis in the socio-economic life of the country and the need to stabilize the state's economy necessitate the formation of the main directions of development of aviation enterprises [14].

Thus, based on the reliability of expert assessment and calculation of integrated weights of groups, we form a scale for estimating the value integrated coefficient of export potential of aviation enterprises (Fig. 1).

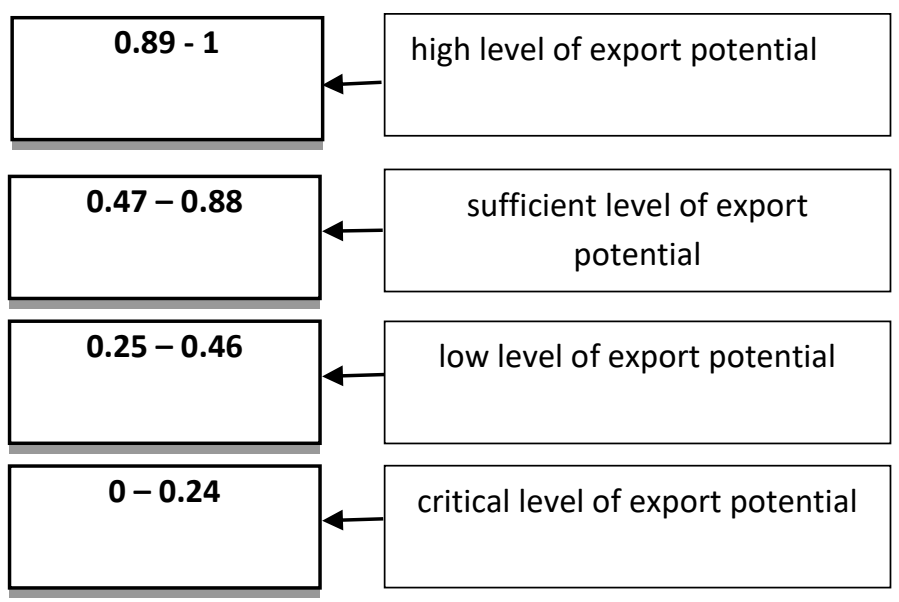

Fig. 1. Scale for determining the level of export potential of airlines.

The value of the integrated coefficient of export potential obtained with the help of the proposed formulas has the following properties: it can vary from 0 to 1 (or from 0 to 100\%); as the value of each shaping factor increases, the integral coefficient of export potential increases in proportion to the significance of the group weighting factor [15].

It can be stated that the enterprises of the aviation complex have specific features inherent in the object of state regulation, the following:

- $\quad$ is in direct interaction with the economic, energy, environmental and social sectors, which ensures its competitiveness and efficiency;

- $\quad$ one of the most capital- and knowledge-intensive industries and one of the leading industries;

- $\quad$ provides for the predominance of the innovation component during the design and manufacture of air transport;

- $\quad$ its effectiveness directly depends on the availability of appropriate state regulation;

- has a direct impact on the state of national security of the state, as it is focused, inter alia, on the design and manufacture of defense products;

- $\quad$ focused on creating competitive products and bringing it to the world market;

- develops both at the expense of the state budget and at the expense of attraction of foreign investments and investments of the business environment (including because of participation in complex international programs with preferential terms of financing, PPP).

\section{Impact}

Considering the peculiarities of the aviation sector, the structure of interaction of enterprises of the aviation complex of Ukraine is proposed, which as a result will allow to form and implement a strategic plan of balanced development and get a synergetic effect from its implementation.

Based on certain approaches, methodological support for forecast analysis of competitiveness and export potential of airlines based on assessing the effectiveness of potential on the criteria of completeness, efficiency, degree of implementation, as well as compliance with market conditions.

The functioning of enterprises that create the basis of export potential, the structure of foreign economic relations and competitiveness of the potential of these airlines, which determine the content and relationship of purpose, object, principles and methods of capacity development to achieve certain goals; the imperfect 
system of state support (preferences and incentives) is analyzed; a detailed classification of aviation goods is given $[1,16]$.

In the process of analysis, approaches to a comprehensive assessment of the export potential of aviation enterprises were established, which allowed to attract more indicators for the analysis of the competitiveness of aviation enterprises in world markets [5]. This made it possible to reorient foreign economic relations for the enterprises of the aviation complex due to the change in the vector of export orientation.

\section{Conclusions}

Strategic potential, according to author [17], "is a very broad category, which covers not only the marginal volume of production of certain products when used in the largest amount of material resources and labor". And this is the ability of the system to analyze the situation of the external environment, to assess market conditions and adapt to external conditions by constantly monitoring changes in demand for goods and services, the implementation of new ideas that can better meet such needs.

The modern enterprise of the aviation complex is a holistic, complex system operating in a dynamic mode. In this regard, it is impossible to draw a clear line between its domestic and foreign economies. Optimal intraeconomic proportions create the basis for the formation of foreign economic relations, and the latter, in turn, contribute to the continuous improvement of the internal capabilities of the aviation complex. In our opinion, the existence of such a double conditionality of the external and internal economy of the enterprise allows us to conclude that the export potential should be considered in the system of economic potential of the enterprise. However, the category of economic potential is also not primary and is part of a more general concept of "aggregate potential of the enterprise", which also includes technical, social potential and intangible assets - image, brand, corporate culture, patents, inventions, etc.

Thus, the main goal in assessing the export potential of the aviation enterprise should be the process of identifying and implementing reserves to increase the efficiency and profitability of export activities of the enterprise, growth of production competitive in foreign markets with minimal production and financial resources.

Kim (2016) applied probabilistic modeling to analyze the impact of changing requirements for the aviation industry during an economic downturn [18]. Derigs and Illing (2013) presented model-based studies of the configuration and optimization of a cargo airline network [19]. Lapp and Cohn (2012) presented a new metric service availability model that measures the throughput and reliability of the planned number of flights [20]. Barnhart et al. (2012) concluded on trends and research opportunities in air travel demand and capacity management; then described a strategic approach to better managing demand and available capacity in terms of defining, allocating and using air traffic capacity [21]. Flores-Fillol (2010) proposed a congestion pricing model to justify the relationship between flight frequency and aircraft size, and carefully assessed the consequences of congestion at hubs [22]. In our opinion, the export potential is a dynamic component of the economic potential of the enterprise, which, based on available and possible resources and means and considering environmental factors, will ensure the company's ability to produce and supply competitive products to foreign markets. As for the allocation of types of export potential of the aviation complex, we propose to divide the realized and unrealized export potential (reserves). The process of identifying and implementing reserves in the formation of export potential is aimed at maintaining a balance between costs and results of the enterprise.

\section{Conflict of interest}

There are no conflicts to declare.

\section{Acknowledgments}

This research has not been supported by any external funding.

\section{References}

[1] O.P. Larsen, A. Tyas, Conceptual Structural Design: Bridging the Gap between Architects and Engineers, Thomas Telford, London, UK, 2003. https://doi.org/10.1680/csdbtgbaae.32354.

[2] G. Gurina, Potential and strategy for the development of Ukraine's aviation complex, Znan. Misel J. 2 (2018) 17-18. 
[3] C. Eastman, P. Teicholz, R. Sacks, K. Liston, BIM Handbook: A Guide to Building Information Modeling for Owners, Managers, Designers, Engineers and Contractors, 2nd ed., John Wiley \& Sons, Inc., Hoboken, NJ, USA, 2011.

[4] M. Oraee, M.R. Hosseini, E. Papadonikolaki, R. Palliyaguru, M. Arashpour, Collaboration in BIM-based construction networks: a bibliometric-qualitative literature review, Int. J. Proj. Manag. 35 (2017) 12881301. https://doi.org/10.1061/(ASCE)ME.1943-5479.0000605.

[5] Y. Jiang, V. Havrysh, O. Klymchuk, V. Nitsenko, T. Balezentis, D. Streimikiene, Utilization of Crop Residue for Power Generation: The Case of Ukraine, Sustain. 11 (2019) 7004. https://doi.org/10.3390/su11247004.

[6] I.V. Khovrak, Financing Innovation Development: Realities and Prospects, Marketing And Innovation Management. 2 (2013) 229-235.

[7] R. Fillol-flores, Congested hubs, Transp. Res. Part B Methodol. 44 (2010) 358-370. https://doi.org/10.1016/j.trb.2009.10.004.

[8] V. Nitsenko, S. Kotenko, I. Hanzhurenko, A. Mardani, I. Stashkevych, M. Karakai, Mathematical Modeling of Multimodal Transportation Risks, in: R. Ghazali, M.M. Deris, N.M. Nawi, J.. Abawajy (Eds.), Recent Adv. Soft Comput. Data Min., Springer Nature Switzerland AG, 2020: pp. 439-447.

[9] E.I. Danilova, S. Petrovska, O.I. Klochkivski, O. Lienko, Features of Activity of Air Carriers in Conditions of the Multiple Environment, Aviat. Transp. 1 (2019) 162-167.

[10] K. Andriushchenko, V. Kovtun, L. Shergina, O. Rozhko, L. Yefimenko, Agro-based Clusters: A Tool for Effective Management of Regional Development in the ERA of Globalization, TEM J. 9 (2020) 198-204. https://doi.org/10.18421/TEM91-28.

[11] G. Gurina, S. Podrieza, N. Liskovych, Prospects for development of export potential of aviation complex of Ukraine on the basis of public-private partnership, Eurasian J. Anal. Chem. 13 (2018) 665-673.

[12] P. Goldberg, N. Pavcnik, Distributional E ects of Globalization in Developing Countries, Journal Econ. Literature. 45 (2007) 39-82. https://doi.org/10.1257/jel.45.1.39.

[13] G. Yip, T. Hult, Total Global Strategy, 3rd ed., Pearson, 2012.

[14] V. Novak, V. Marchenko, V. Perederii, Scientific basis of management of transport companies interaction, Airtransport. 1 (2016) 31-36.

[15] E. Ametova, Formation and development of export potential of enterprises, (2014).

[16] A. V. Liezina, K.A. Andriushchenko, O.D. Rozhko, O.I. Datsii, L. Mishchenko, O.O. Cherniaieva, Resource planning for risk diversification in the formation of a digital twin enterprise, Accounting. 6 (2020) 1337-1344. https://doi.org/10.5267/j.ac.2020.8.016.

[17] Z. Pezeshki, A. Soleimani, Applications of BIM: a brief review and future outline, Arch. Comput. Methods Eng. 25 (2018) 273-312. https://doi.org/10.1007/s11831-016-9204-1.

[18] Z. Xu, T. Huang, B. Li, H. Li, Q. Li, Developing an IFC-based database for construction quality evaluation, Adv. Civ. Eng. 2018 (2018) 22. https://doi.org/10.1155/2018/3946051.

[19] M.K. Amy, The impacts of changing flight demands and throughput performance on airport delays through the Great Recession, Transp. Res. Part A Policy Pract. 86 (2016) 19-34. https://doi.org/10.1016/j.tra.2016.02.001.

[20] U. Derigs, S. Illing, Does EU ETS instigate Air Cargo network reconfiguration? A model-based analysis, Eur. J. Oper. Res. 225 (2013) 518-527. https://doi.org/10.1016/j.ejor.2012.10.016.

[21] M. Lapp, A. Cohn, Modifying lines -of-flight in the planning process for improved maintenance robustness, Comput. Oper. Res. 39 (2012) 2051-2062. https://doi.org/10.1016/j.cor.2011.08.024.

[22] C. Barnhart, D. Bertsimas, C. Caramanis, D. Fearing, Equitable and Efficient Coordination in Traffic Flow Management, Transp. Sci. 46 (2012) 262-280. https://doi.org/10.1287/trsc.1110.0393. 